\title{
4-Acetylantroquinonol B inhibits lipopolysaccharide-induced cytokine release and alleviates sepsis through of MAPK and NFKB suppression
}

Chien-Hsin Chang ${ }^{1}$, Chun-Chieh Hsu ${ }^{1,2}$, An-Sheng Lee ${ }^{3}$, Shih-Wei Wang ${ }^{3}$, Kung-Tin Lin' ${ }^{1}$ Wei-Luen Chang ${ }^{1}$, Hui-Chin Peng ${ }^{1}$, Wen-Chiung Huang ${ }^{4}$ and Ching-Hu Chung ${ }^{3^{*}}$ (D)

\begin{abstract}
Background: Antrodia cinnamomea is an indigenous medicinal mushroom in Taiwan, commonly used for the treatment of cancers and inflammatory disorders. 4-acetylantroquinonol B (4AAQB) is one of the active component isolated from the mycelium of A. cinnamomea. However, whether 4 AAQB exhibits anti-inflammatory effect is not clear.

Methods: The anti-inflammatory activity of $4 A A Q B$ was examined by ELISA to measure the pro-inflammatory cytokines production in lipopolysaccharide (LPS)-simulated RAW264.7 cells, peritoneal macrophages and in mice. The effect of $4 A A Q B$ for MAPK kinase molecules phosphorylation in LPS-stimulated RAW264.7 macrophage including ERK, JNK and p38 were evaluated. The in vivo efficacy of $4 A A Q B$ was also demonstrated.

Results: In the present study, we found that $\triangle A A Q B$ exhibits anti-inflammatory effects inhibit tumor necrosis factor-a (TNF-a)/interleukin-6 (IL-6) releasing and LPS-stimulated phagocytes migration without affect cell growth. In addition, the MAPK kinase molecules phosphorylation in LPS-stimulated RAW264.7 macrophage including ERK, JNK and p38 was inhibited by $4 A A Q B$. The phosphorylation of NFKB subunit p65 and IkBa were also decreased after $4 A A Q B$ treatment. Furthermore, $4 A A Q B$ attenuates the cytokine production in LPS-induced and CLP-induced septic mice.
\end{abstract}

Conclusion: These results showed that $4 A A Q B$ exhibited anti-inflammatory property both in vitro and in vivo, suggesting that $\triangle A A Q B$ may be a therapeutic candidate which used in inflammatory disorders treatment.

Keywords: Antrodia cinnamomea, $4 A A Q B$, Anti-inflammation, MAPK, NFKB

\section{Background}

Inflammation is an adaptive response which is triggered by harmful stimuli such as tissue injury and infection $[1,2]$. In response to invading pathogens, macrophages activate and release proinflammatory cytokines (TNF- $\alpha$, IL-6, IL-1 $\beta$ ) and proinflammatory mediators like cyclooxygenase (COX)-2, and nitric oxide (NO) [3]. Overproduction of these pro-inflammatory cytokines and mediators causes sustained inflammation which can lead to numerous

\footnotetext{
* Correspondence: chchung@mmc.edu.tw

${ }^{3}$ Department of Medicine, Mackay Medical College, No. 46, Sec. 3 ,

Jhong-Jheng Rd., Sanzhi Dist, New Taipei City, Taiwan

Full list of author information is available at the end of the article
}

diseases like atherosclerosis, cancer, and cardiovascular disease.

Sepsis is a systemic inflammatory response and finally resulting in multiple organ dysfunction, refractory hypotension, and high mortality [4]. Lipopolysaccharide (LPS) was an endotoxin derived from gram-negative bacteria which interacts with monocytes/macrophages and lead to the production of pro-inflammatory cytokines and mediators [5]. Toll-like receptor 4 (TLR-4) recognizes LPS and leads to the activation of intracellular signaling proteins, including mitogen-activated protein kinase (MAPK) and Nuclear Factor-kB (NFkB) [6]. 
Antrodia cinnamomea (A. cinnamomea) is a traditional medicine and a unique fungus originating from Taiwan. This Chinese medicinal herb was widely used for abdominal pain, inflammatory disorders, liver diseases, and cancer treatment $[7,8]$. Previous studies have shown that A. cinnamomea exhibits various pharmacological effects including anti-cancer, anti-inflammatory and antioxidative and hepatoprotective activities [7, 9-11]. 4-acetylantroquinonol B (4AAQB), isolated from the mycelium of A. cinnamo$m e a$, was previously demonstrated to inhibit the growth of hepatocellular carcinoma cells [12]. Recent studies showed that $4 \mathrm{AAQB}$ exhibited inhibitory effects on hepatoma cell growth via cell cycle and PI3K/Akt/mTOR pathways inhibition, and further displayed prominent anti-tumor growth and its metastatic in vivo $[13,14]$. While 4AAQB has been shown previously to inhibit nitric oxide production induced by LPS in murine macrophages [15], the molecular mechanisms underlying the effect produced by 4AAQB have not been characterized so far. Moreover, there are very limited studies investigate the anti-inflammation efficacy in in vivo models about $4 \mathrm{AAQB}$ and other related antroquinonol derived. In this study, we found that 4AAQB may modulate the MAP kinases and NFkB signaling pathways and decrease inflammatory cytokines to possess its anti-inflammatory effects. Furthermore, 4AAQB displayed prominent anti-inflammation effects in LPS and CLP-induced sepsis mice models.

\section{Methods}

\section{Plant material}

Antrodia cinnamomea (BCRC35716) was obtained from the Bioresources Collection and Research Center (BCRC) (Hsinchu, Taiwan). A voucher specimen (MMC-002) was deposited in the Department of Medicine, Mackay Medical College (New Taipei City, Taiwan). 4Acetylantroquinonol B was isolated from the mycelium of A. cinnamomea as described previously [12]. After the end of the fermentation process, the mycelial ethanol extract was re-dissolved in water and extracted with ethyl acetate. The water layer was then extracted with water saturated n-butanol and was further purified by silica gel chromatography and high-performance liquid chromatography. The structure of the $4 \mathrm{AAQB}$ was identified by nuclear magnetic resonance (NMR; AMX-400, Bruker, Billerica, MA, USA) and the detail information about identifying 4AAQB was shown in Additional file 1.

\section{Chemical materials}

The enzyme-linked immunosorbent assays (ELISA) kit for TNF- $\alpha$ and IL- 6 were from eBioscience (San Diego, CA, USA). DMEM, FBS, and all culture reagents were purchased from Gibco BRL (Life technologies, USA). Antibodies against p38, phosphorylated p38, JNK, phosphorylated JNK, ERK, phosphorylated ERK, $\alpha$-tubulin,
iNOS, phosphorylated NFkB p65 were purchased from Santa Cruz (Biotechnology, Inc., USA). $\beta$-actin antibody was from Novus Biologicals (Littleton, CO, USA). Antibodies against phosphorylated $\mathrm{I} \kappa \mathrm{B} \alpha$, phosphorylated STAT1 were purchased from Cell Signaling Technologies (Boston, MA, USA). Lipopolysaccharide (LPS, from E. coli, 0127: B8), gelatin, dexamethasone (Dex) and other chemicals were purchased from Sigma Chemicals, Co. (St Louis, Mo, USA).

\section{Cell cultures}

The RAW264.7 macrophage cell line was obtained from American Type Culture Collection. The cells were cultured at $37^{\circ} \mathrm{C}$ in HEPES-buffered Dulbecco's modified Eagle's medium (DMEM), containing 10\% fetal bovine serum (Gibco) supplemented with $\mathrm{NaHCO} 3$, glutamax I (Gibco), $100 \mathrm{IU} / \mathrm{mL}$ penicillin G (sodium salt), $100 \mu \mathrm{g} / \mathrm{mL}$ streptomycin, and $0.25 \mu \mathrm{g} / \mathrm{mL}$ amphotericin B (antibiotic -antimitotic solution, Gibco). Murine peritoneal macrophage cells were elicited by intraperitoneal injection of $1 \mathrm{ml}$ of $4 \%(w / v)$ thioglychollate into the peritoneal cavity of 4 weeks old BALB/c male mice [16]. The animals were maintained on a 12-h light/dark cycle under controlled temperature $\left(20 \pm 1{ }^{\circ} \mathrm{C}\right)$ and humidity $(55+5 \%)$ and were given continuous access to food and water. After 5 days, peritoneal exudates cells were obtained by lavage with $10 \mathrm{ml}$ ice-cold DMEM. The harvested cells were treated with ACK lysis buffer $(0.15 \mathrm{M} \mathrm{NH} 4 \mathrm{Cl}, 10 \mathrm{mM}$ KHCO3, $0.1 \mathrm{mM}$ EDTA) for $1 \mathrm{~min}$ to lyse the red blood cells. After removing the ACK lysis buffer, the cells were washed twice and resuspended in HEPES-buffered DMEM and were seeded in sterile disposable culture plates.

\section{Cell viability assay}

Cell viability was determined by 3-(4,5-dimethyl-thiazol-2yl)-2,5-diphenyl tetrazolium bromide (MTT; Sigma, St Louis, MO, USA) reduction assay. In brief, RAW264.7 cells and murine peritoneal macrophage cells were preincubated overnight in 48-well plates at a density of $2 \times 10^{5}$ cells/well (murine peritoneal macrophage cells) of $5 \times 10^{4}$ cells/well (RAW264.7 cells) and were then treated with various concentrations of 4AAQB coexisted with LPS $(100 \mathrm{ng} / \mathrm{mL})$. After LPS stimulation for $24 \mathrm{~h}$, the culture supernatants were replaced with MTT $(0.5 \mathrm{mg} / \mathrm{ml})$ at $37{ }^{\circ} \mathrm{C}$ with $5 \% \mathrm{CO} 2$ for $30 \mathrm{~min}$. The resulting dark blue crystals were then dissolved in DMSO (200 ul/well) after the MTT was removed. Absorbance values were read at $550 \mathrm{~nm}$ with an automated Spectra MAX 340 (Molecular Devices, Sunnyvale, CA, USA). All determinations were obtained by replication in at least three independent experiments.

\section{Cytokine assays}

RAW264.7 cells and murine peritoneal macrophage cells were plated onto 48 -well plates at a density of $2 \times 10^{5}$ 
cells/well, and then treated with various concentrations of $4 \mathrm{AAQB}$ or positive control (Dexamethasone, Dex) coexisted with LPS (100 ng/ml) for $24 \mathrm{~h}$. The cell supernatants were collected by centrifugation. Cytokines were measured by ELISA kit according to the manufacture's instruction.

\section{Migration assay}

Migration assay of murine peritoneal macrophage cells was measured by Coaster Transwells (polycarbonate filter, $5 \mu \mathrm{m}$ pore size), which were coated with $0.2 \%$ gelatin. Murine peritoneal macrophage cells $\left(1 \times 10^{5}\right.$ cells/well $)$ were incubated with vehicle or different concentrations of $4 \mathrm{AAQB}$ at $37{ }^{\circ} \mathrm{C}$ for $30 \mathrm{~min}$ and then treated with LPS $(100 \mathrm{ng} / \mathrm{ml})$, and cells were seeded into the upper chamber. After incubation at $37{ }^{\circ} \mathrm{C}$ for $20 \mathrm{~h}$, the macrophages that had transmigrated and bound to the membrane were fixed with $4 \%$ paraformaldehyde and stained with $0.5 \%$ toluidine. Migration was quantified by counting the number of stained cells with light microscope (Nikon, Japan) in 3 random fields $(200 x)$ and then photographed. All determinations were obtained by replication in at least three independent experiments.

\section{Nitric oxide assay}

The nitrite accumulated in the culture medium was measured as an indicator of nitric oxide (NO) production based on the Griess reaction [17]. In brief, RAW264.7 cells were treated with or without LPS $(100 \mathrm{ng} / \mathrm{ml})$ in the presence of various concentrations of $4 \mathrm{AAQB}$. After $24 \mathrm{~h}$, culture supernatants were mixed with Griess reagent [equal volumes of $1 \%(w / v)$ sulfanilamide in $5 \%(v / v)$ phosphoric acid and $0.1 \%(\mathrm{w} / \mathrm{v})$ naphtylethylenediamine$\mathrm{HCl}$, and incubated at room temperature for $10 \mathrm{~min}$. Absorbance values were read at $550 \mathrm{~nm}$ and NO concentration was calculated with reference to a standard curve of sodium nitrite.

\section{Western blot analysis}

RAW 264.7 cells $\left(2 \times 10^{5}\right.$ cells $\left./ \mathrm{ml}\right)$ and murine peritoneal macrophage cells were plated onto 6-well plates and pretreated with $4 \mathrm{AAQB}$ for $30 \mathrm{~min}$ and then stimulated with the presence or absence of $100 \mathrm{ng} / \mathrm{ml} \mathrm{LPS} \mathrm{for} 6 \mathrm{~h}$ (for iNOS), $30 \mathrm{~min}$ (for MAPKs and $\mathrm{I} \kappa \mathrm{B} \alpha$ ). Aliquots of total cell lysates or cell membrane fractions were analyzed by Western blotting. For quantification of the Western analysis, the density of each band was quantified by ImageJ software.

\section{Animals}

Male ICR mice was obtained from BioLASCO Taiwan. Male ICR mice weighing 25-30 g were used in the animal model. All the experimental protocols regarding animal studying have been approved by the Laboratory Animal Use Committee of MacKay Medicine College.

\section{LPS-induced endotoxemia}

Mice were anesthetized with inhalation anesthetic drug (Isoflurane) and injected intraperitoneally (i.p.) with DMSO (as control, $20 \mu \mathrm{l}$ ) or 4AAQB (0.3, 1 and $3 \mathrm{mg} /$ $\mathrm{kg}$ ) (10 mice in each group). Mice were injected intraperitoneally (i.p.) with LPS $(20 \mathrm{mg} / \mathrm{kg}) 30$ mins later. Mice were sacrificed $24 \mathrm{~h}$ after LPS and drug treatment. The health of mice was monitored every $6 \mathrm{~h}$ and record the mice number of survival. After experiment, all animals were euthanasia with $\mathrm{CO} 2$.

\section{Cecal Ligation Puncture (CLP)-induced sepsis}

Mice were anesthetized with inhalation anesthetic drug (Isoflurane,) and then injected intraperitoneally (i.p.) with DMSO (as control, $20 \mu \mathrm{l}$ ) or 4AAQB (0.3 and $3 \mathrm{mg} / \mathrm{kg}$ ) (13 mice in control group and 8 mice each in 4AAQB (0.3 and $3 \mathrm{mg} / \mathrm{kg}$ ) group). Next, a 2-cm midline incision was performed to allow exposure of the cecum with adjoining intestine. The cecum was tightly ligated with a 3.0 -silk suture at $1 \mathrm{~cm}$ from the cecal tip and punctured once with a 23-gauge needle. The cecum was then gently squeezed to extrude a few feces from the perforation sites and returned to the peritoneal cavity. The laparotomy site was the stitched with 4.0 silk. In control mice, the cecum was exposed but not ligated or punctured and then returned to the abdominal cavity. The health of mice was monitored every day and record the mice number of survival. After experiment, all animals were euthanasia with $\mathrm{CO} 2$.

\section{Mice whole blood and serum collection}

After injecting intraperitoneally (i.p.) with LPS or CLP operation for $24 \mathrm{~h}$, mice were anesthetized by i.p. injection of sodium pentobarbital $(50 \mathrm{mg} / \mathrm{kg})$ and whole blood was drawn by cardiac puncture or from the eye holes and collected in citric acid-citrate dextrose $(\mathrm{ACD} ; 9: 1$ blood $v / \mathrm{v})$ at indicated time. The sera were obtained by centrifugation at $1000 \times \mathrm{g}$ for $10 \mathrm{~min}$. After these studies finished, we used carbon dioxide $\left(\mathrm{CO}_{2}\right)$ overdose to euthanasia for all animals.

\section{Measurement of cytokine levels}

The concentration of cytokines, TNF- $\alpha$ and IL- 6 , in the sera was determined by ELISA kit according to the manufacture's instruction.

\section{Histological examination}

Lung, liver, kidney segments were cut off and fixed in $10 \%(\mathrm{v} / \mathrm{v})$ phosphate-buffered formalin for $48-72 \mathrm{~h}$ and then embedded in paraffin. Next, the samples were sectioned $(5 \mathrm{~mm})$ using a microtome, stained 
with $\mathrm{H} \& \mathrm{E}$, and examined with light microscopy at $400 \times$ magnifications.

\section{Statistical analysis}

All values are presented as mean \pm S.E.M. Differences between groups were assessed by one-way ANOVA and Newman-Keuls multiple comparison tests where appropriate. $P$ values less than $0.05(p<0.05)$ were considered as significant difference.

\section{Results}

Effects of $\triangle A A Q B$ on cell viability in murine macrophage cell line and peritoneal macrophage

Firstly, we evaluated the effects of $4 \mathrm{AAQB}$ on cell viability of RAW264.7 murine macrophages and peritoneal macrophages using MTT cell viability assay. The cytotoxic effect was tested to find the appropriate concentration ranges of $4 \mathrm{AAQB}$ for the ongoing experiments. Figure 1 showed that $4 \mathrm{AAQB}$ has a cytotoxicity for LPS-stimulated RAW 264.7 cells and peritoneal macrophages at $50 \mu \mathrm{g} / \mathrm{ml}$. We use the non-toxic concentrations (1 to $25 \mu \mathrm{g} / \mathrm{ml}$ ) of $4 \mathrm{AAQB}$ to perform the following experiments.

\section{AAQB inhibits TNF- $a$ and IL- 6 production in LPS- stimulated phagocytes}

We further determine pro-inflammatory cytokines production affect by 4AAQB in LPS-stimulated RAW264.7 macrophages and peritoneal macrophages. Cells treated with LPS obviously increased the pro-inflammatory cytokines production, including TNF- $\alpha$ and IL-6. 4AAQB (1$25 \mu \mathrm{g} / \mathrm{ml}$ ) inhibited the protein levels of TNF- $\alpha$ and IL- 6 production in a concentration-dependent manner both in RAW264.7 macrophages (Fig. 2a-b) and peritoneal macrophages (Fig. 2c-d). There is no significant difference between control and vehicle groups. As a positive control, dexamethasone $(10 \mu \mathrm{M})$ also have the ability to inhibit LPS-induced cytokine release.
4AAQB inhibits LPS-stimulated peritoneal macrophages migration

During inflammation, monocytes/macrophages enable to infiltrate from blood vessels to extravascular sites. Therefore, transwells (gelatin-coated) were used to evaluate the effect of $4 \mathrm{AAQB}$ on LPS-stimulated migration of peritoneal macrophages. 4AAQB displayed concentration-dependent inhibitory effect on peritoneal macrophages migration of (Fig. 3). There is no significant difference between control and vehicle groups.

4AAQB inhibits the inducible nitric oxide synthase (iNOS) expression and NO production in LPS-stimulated macrophage Upon LPS stimulation, the expression of iNOS is increased, which in turn produce more amounts of $\mathrm{NO}$ [18]. The nitrite production and iNOS expression increasing were observed in LPS $(100 \mathrm{ng} / \mathrm{ml})$ stimulated RAW macrophages. 4AAQB treatment was able to reduce NO production (Fig. 4a) and iNOS expression induced by LPS (Fig. 4b), indicating that $4 \mathrm{AAQB}$ inhibits NO production and iNOS expression at the transcriptional level.

\section{AAQB inhibits the MAPK signaling pathway} phosphorylation in LPS-stimulated macrophages MAPK molecules are important to regulate proinflammatory cytokines and NO production from activated macrophages and involved in inflammation and sepsis [19]. We further investigate the involvement of these MAPK molecules phosphorylation in $4 \mathrm{AAQB}$ anti-inflammatory mechanisms. The phosphorylation of extracellular signal-related kinase 1/2 (ERK1/2), p38 MAP kinase (p38) and c-Jun $\mathrm{NH} 2$-terminal kinase (JNK) was induced by LPS stimulation rapidly within $30 \mathrm{~min}$ in RAW264.7 cells and the total ERK1/2, p38, and JNK protein were not changed. There is no significant difference between control and vehicle groups. $4 \mathrm{AAQB}$ suppressed the phosphorylation of these MAPK molecules in LPS-stimulated macrophages in a concentration dependent manner (Fig. 5a).
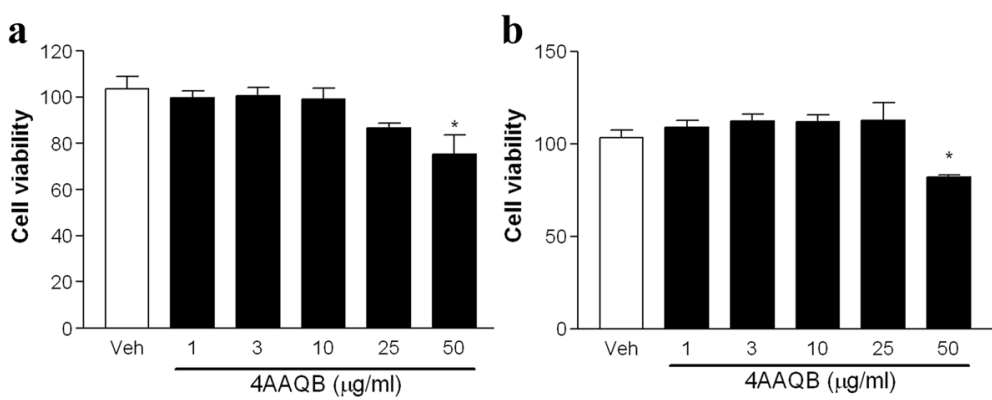

Fig. 1 Effect of $4 A A Q B$ on cell viability of murine macrophages stimulated with lipopolysaccharides (LPS). RAW264.7 macrophages (a) or peritoneal macrophages (b) were incubated with various concentrations of $4 A A Q B$ in the presence of LPS $(100 \mathrm{ng} / \mathrm{ml})$ for $24 \mathrm{~h}$. Cell viability was determined by MTT assay. Data are expressed as the mean \pm S.E.M of three independent experiments and ${ }^{*} p<0.05$ as compared with DMSO vehicle group 

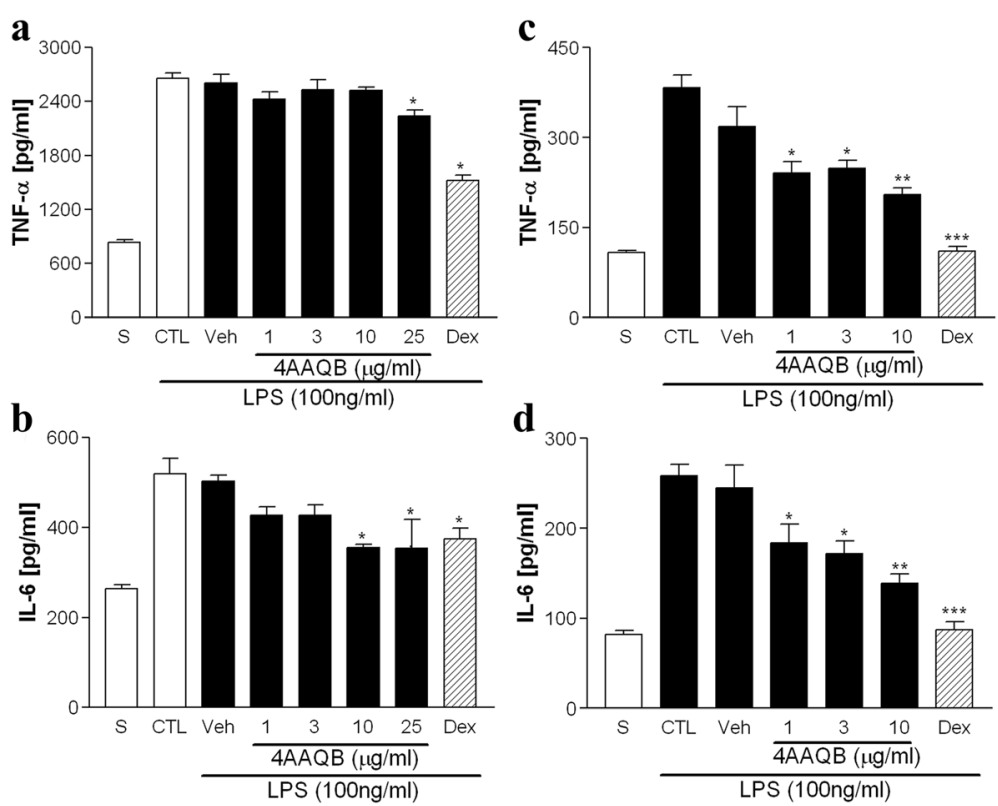

Fig. 2 Effect of $4 A A Q B$ on TNFa and IL-6 production in LPS-stimulated macrophages. RAW264.7 macrophages (a, b) or peritoneal macrophages (c) d) were pretreated with various concentrations of $4 A A Q B$ of dexamethasone (Dex, $10 \mu \mathrm{M})$ for $30 \mathrm{~min}$, and then activated with LPS (100 ng/ml) for $24 \mathrm{~h}$. The TNFa and IL-6 concentrations were measured by ELISA kits. Results are showed as mean \pm S.E.M of three independent experiments. ${ }^{*} p<0.05,{ }^{* *} p<0.01$ and ${ }^{* * *} p<0.001$ as compared with LPS-treated groups

a

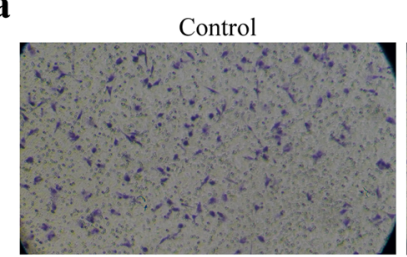

$4 \mathrm{AAQB} 3 \mu \mathrm{g} / \mathrm{ml}$

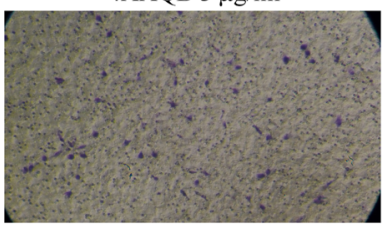

$\mathbf{b}$

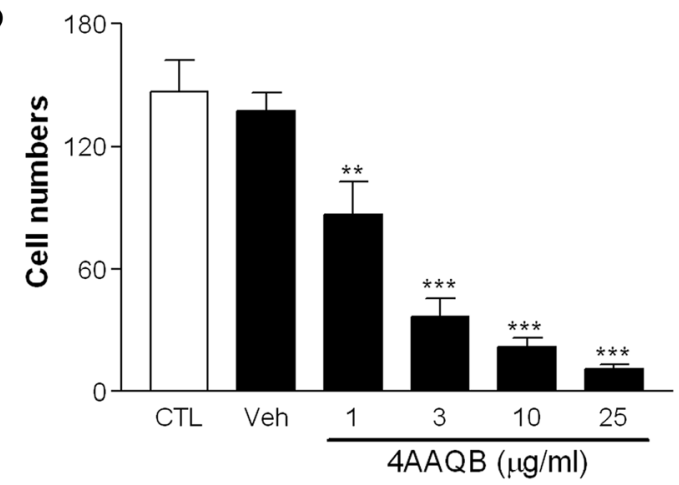

Fig. 3 Effect of $4 A A Q B$ on LPS-induced cell migration of murine macrophages. Peritoneal macrophages were pretreated with various concentrations of $4 A A Q B$ for 30 min and then activated with LPS. The results of cell migrated through gelatin-coated transwells for $20 \mathrm{~h}$ were shown (a), and the migrated cells were counted (b). Data are expressed as the mean \pm S.E.M of three independent experiments. ${ }^{* *} p<0.01$ and ${ }^{* * *} p<0.001$ as compared with LPS-treated control groups (CTL) 


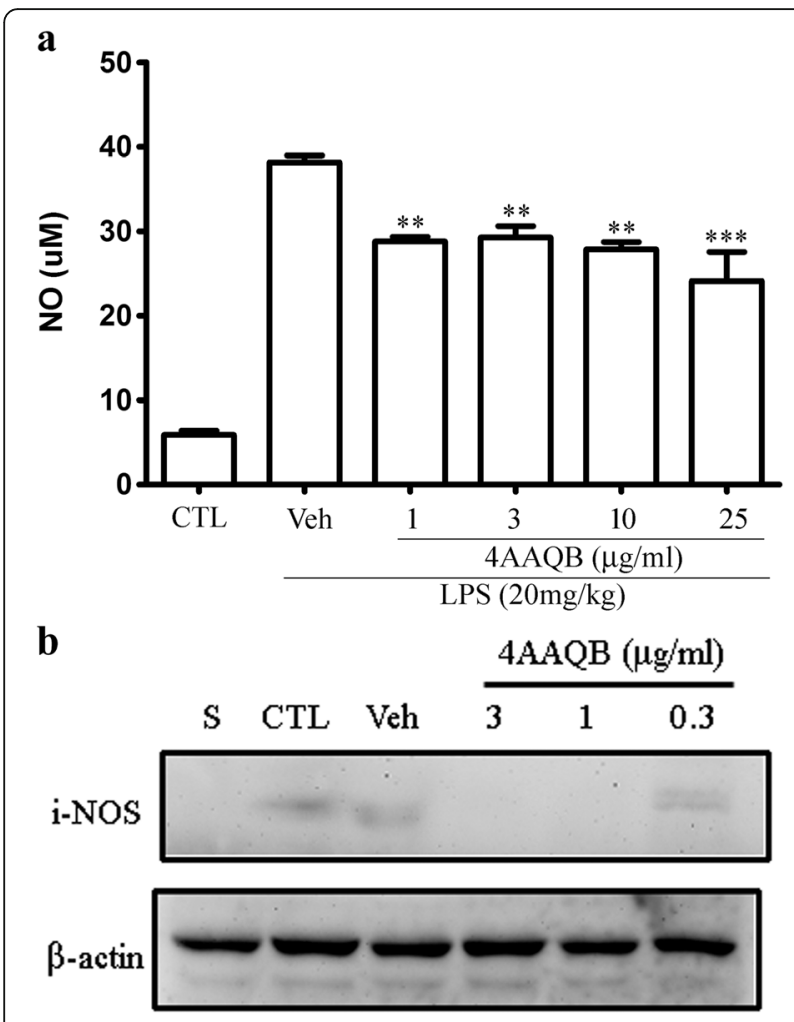

Fig. 4 The effects of $4 A A Q B$ on LPS-induced nitric oxide production and iNOS expression in RAW264.7 macrophages. a The cells were treated with LPS $(100 \mathrm{ng} / \mathrm{ml})$ only or with various concentrations of $\triangle A A Q B$ and the nitric oxide production was measured after $24 \mathrm{~h}$. Control $(C T L)$ values were obtained in the absence of LPS. Data were obtained from three independent experiments and expressed as means \pm S.E.M. ${ }^{*} p<0.05$ compared with the LPS-activated only group. b RAW264.7 cells were treated with various concentration of 4AAQB and stimulated with LPS $(100 \mathrm{ng} / \mathrm{ml})$. Cells were harvested and iNOS was detected. Each experiment has been performed three times

Effects of $4 A A Q B$ on NFKB and signal transducer activator of transcription 1 (STAT-1) activation in LPS-stimulated macrophages

During the inflammatory response to LPS, NFKB plays an important role in regulating the pro-inflammatory cytokines, chemokines, adhesion molecules and inducible enzymes expression such as iNOS [20]. Phosphorylation and degradation of $I_{\kappa} \mathrm{B} \alpha$ lead to $\mathrm{NF} \kappa \mathrm{B}$ dissociate from the cytoplasmic $N F \kappa B / I \kappa B \alpha$ complex and subsequently translocate to the cell nucleus in the inflammatory process. We further determine whether 4AAQB affects the signaling pathways involved in $\mathrm{NFKB}_{K}$ activation. As shown in Fig. 5b, we observed that LPS-induced of $\mathrm{I} \kappa \mathrm{B} \alpha$ and NFкB p65 phosphorylation was suppressed by $4 \mathrm{AAQB}$ in a concentration-dependent manner. There is no significant difference between control and vehicle groups, but the phosphorylation of STAT1 in LPS-stimulated RAW264.7 cells is inhibited by 4AAQB (Fig. 5c).
Taken together, our result indicated that $4 \mathrm{AAQB}$ suppresses LPS-induced inflammatory response via NF$\mathrm{kB}$ and STAT-1 inhibition.

\section{Effects of 4AAQB on ERK phosphorylation in LPS- stimulated peritoneal macrophage}

To ensure the 4AAQB have similar inhibitory effect in murine peritoneal macrophage, the ERK1/2 phosphorylation in murine peritoneal macrophage was also studied. The phosphorylation of ERK1/2 was induced by LPS stimulation rapidly within $30 \mathrm{~min}$ in murine peritoneal macrophage and the total ERK $1 / 2$ was not changed (Fig. 5d). There is no significant difference between control and vehicle groups.

\section{AAQB inhibits pro-inflammatory cytokines and NO production in LPS-induced endotoxemia in vivo}

The effect of $4 A A Q B$ on acute inflammation in vivo was tested by LPS-induced endotoxemic model. Mice were injected (intraperitoneally, i.p.) with DMSO (vehicle) or 4AAQB (0.3 and $3 \mathrm{mg} / \mathrm{kg}$ ) and after $30 \mathrm{~min}$ i.p. injected with LPS $(20 \mathrm{mg} / \mathrm{kg})$. The cytokine and NO release were measured by collected mice serum after $24 \mathrm{~h}$. The LPS caused elevated plasma TNF- $\alpha$ and IL- 6 levels were observed and 4AAQB administration concentrationdependently decreased these cytokine levels (Fig. 6a and b). The nitrite production was also reduced by $4 A A Q B$ treatment (Fig. 6c). These results indicated that $4 A A Q B$ have the ability to reduce cytokine and NO release in LPS-induced septic mice.

\section{AAQB increases survival rate of mice and inhibits pro-inflammatory cytokines production in CLP surgery} We also used another inflammation model, cecal ligation puncture (CLP)-induced septic model to test the 4AAQB anti-inflammatory effect. Mice were i.p. injected with DMSO (vehicle) or $4 \mathrm{AAQB}(0.3$ and $3 \mathrm{mg} / \mathrm{kg}$ ) 30 min before the CLP surgery. The survival rate was checked at indicated time point, $4 \mathrm{AAQB}$ administrated group notably has higher survival rate at different time points. As shown in Fig. 7a, the survival rate significantly increases in 4AAQB (0.3 mg/kg)-treated group (from $69.2 \%$ to $12.5 \%$ ) and $4 \mathrm{AAQB}(3 \mathrm{mg} / \mathrm{kg}$ )-treated group (from $69.2 \%$ to $0 \%$ ). The TNF- $\alpha$ and IL-6 release were measured by collected mice serum after surgery $24 \mathrm{~h}$ (Fig. 7b).

\section{Protective effects of $4 A A Q B$ on tissue injury in CLP-induced sepsis model}

The kidney in CLP-induction mice was damaged with glomerular hypercellularity as compared with sham group (Fig. 8a and b). The liver sections in CLPinduction mice also exhibited significant peri-vascular leukocyte infiltration as compared with sham group 


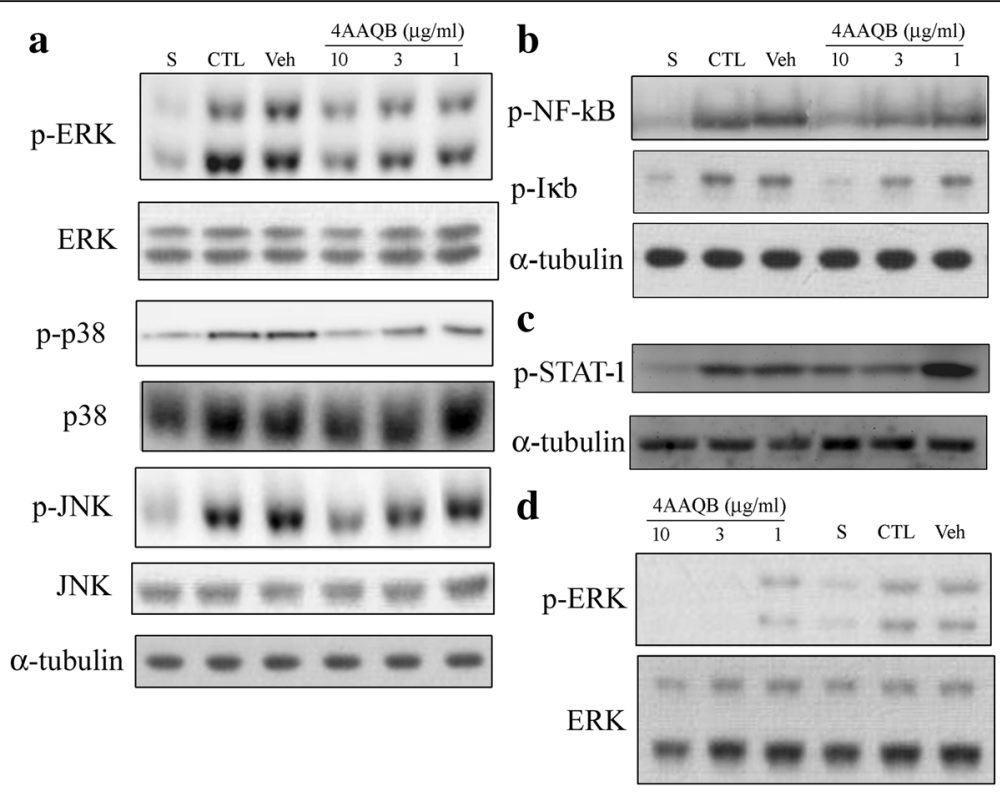

Fig. 5 Effects of $4 A A Q B$ on the LPS-induced activation of MAP kinases, IkBa, NFKB p65 and STAT1 in RAW 264.7 macrophages and peritoneal macrophages. RAW264.7 cells were treated with various concentration of 4AAQB and stimulated with LPS (100 ng/ml) for $30 \mathrm{~min}$. Cells were harvested and total cell extracts were prepared. a Phosphorylated-ERK, phosphorylated-JNK, phosphorylated-p38, or b Phosphorylated-IKBa and NFKB p65 subunit and c Phosphorylated-STAT1 were detected by Western blot analysis. Total ERK, JNK, p38 and a-tubulin were used as internal standard. d Peritoneal macrophages were treated with various concentration of 4AAQB and stimulated with LPS (100 $\mathrm{ng} / \mathrm{ml})$ for $30 \mathrm{~min}$. Phosphorylated-ERK and total ERK were detected by Western blot analysis
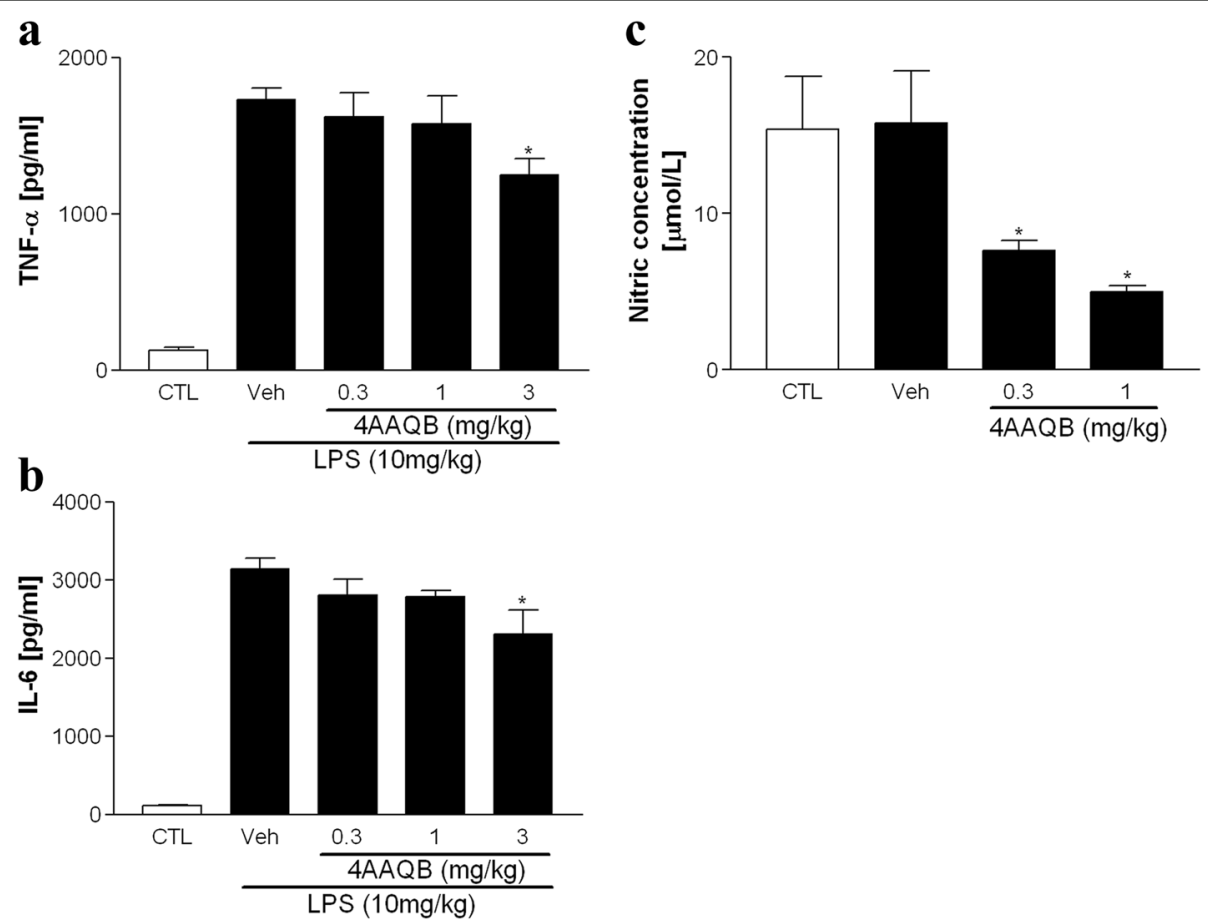

Fig. 6 The effects of $4 A A Q B$ on LPS-induced cytokines and NO release. ICR mice (25-30 g) were treated with 4AAQB and induction of endotoxemia with LPS (20 mg/kg) after $30 \mathrm{~min}$. After $24 \mathrm{~h}$, mice were euthanized collect blood by cardiac puncture. The serum was obtained and the cytokines TNFa/IL-6 (a and $\mathbf{b})$ and NO (c) were measured. Values are presented as mean \pm S.E.M. $(n=10) .{ }^{*} p<0.05$ as compared with the LPS-activated group 


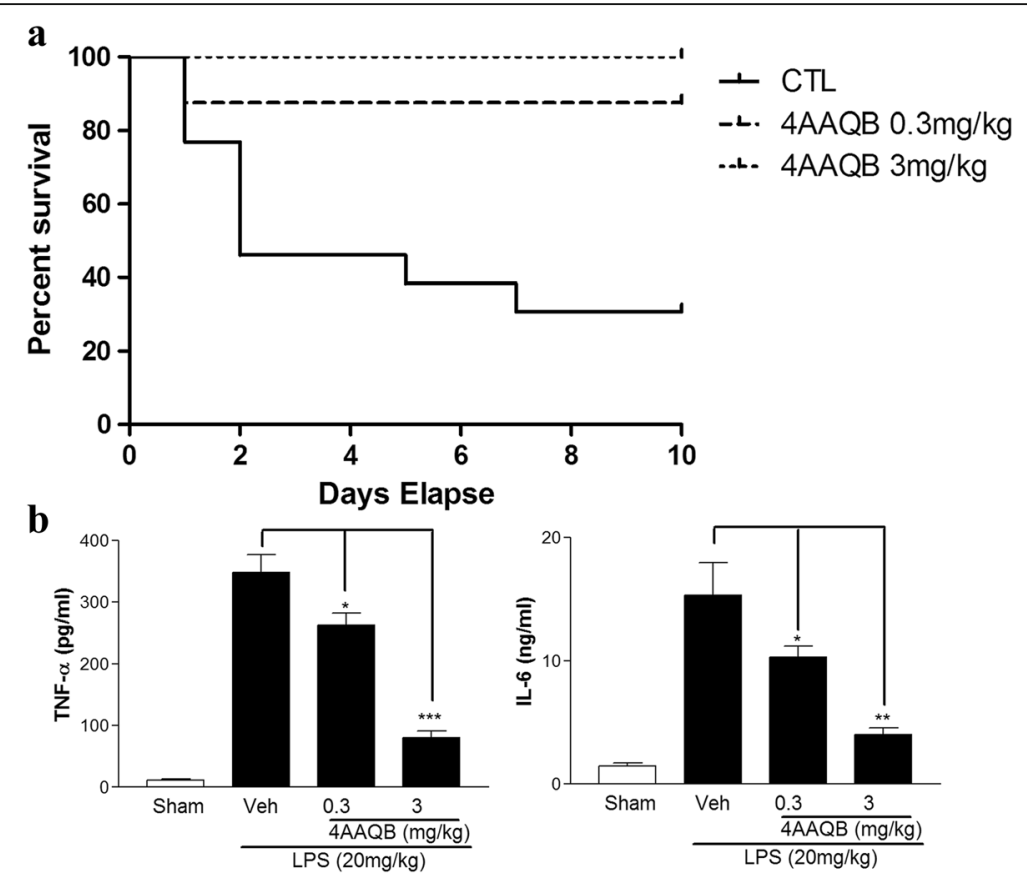

Fig. 7 The protective effects of $4 A A Q B$ on survival rate, cytokine production and tissue inflammation induced by CLP operation in vivo. Mice were administered with 4 AAQB $(0.3$ and $3 \mathrm{mg} / \mathrm{kg}$, i.p., $n=8)$ in DMSO or DMSO (CTL, $n=13)$ for $30 \mathrm{~min}$, and then conducted CLP operation. a Survival was monitored for up to 10 days. Values are presented as mean + S.E.M. ${ }^{*} \mathrm{p}<0.05$ as compared with the LPS-activated group. b Mice were anesthetized and blood was collected for serum isolation $24 \mathrm{~h}$ after CLP operation, and concentration of cytokines was measured by ELISA. Values are presented mean + S.E.M. and ${ }^{*} \mathrm{p}<0.05$ compared with LPS-treated control group

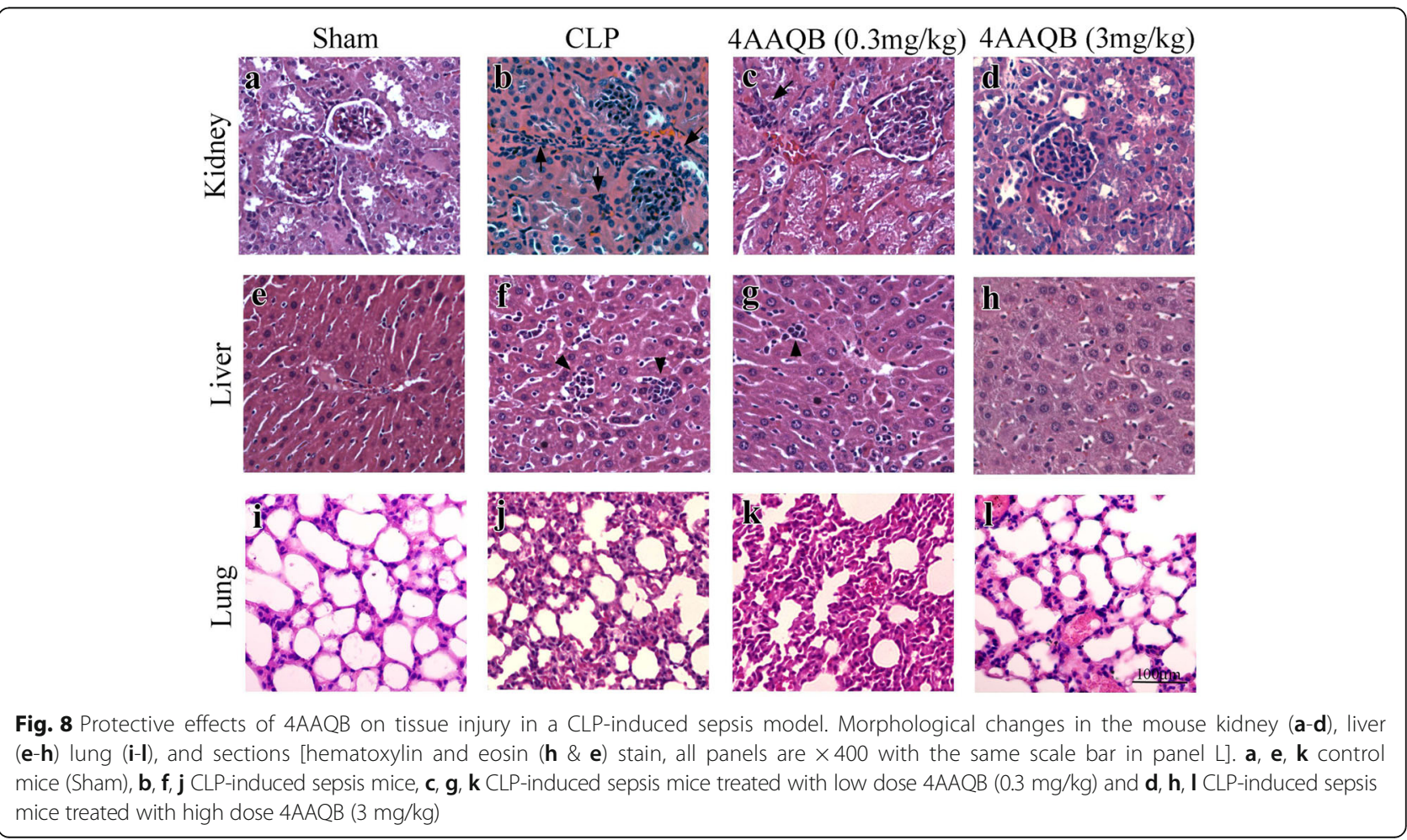


(Fig. 8e and f). The lung sections in CLP-induced septic mice was also present much higher leukocytes infiltration in the alveoli and alveolar wall thickens (Fig. $8 \mathrm{i}$ and $\mathrm{j}$ ). The protective effects of $4 \mathrm{AAQB}$ for these organ injuries in CLP-induced septic mice were shown by in Fig. 8c, g, and $\mathrm{k}$ (low dose, $0.3 \mathrm{mg} / \mathrm{kg}$ ) and Fig. $8 \mathrm{~d}$, h and $\mathrm{l}$ (high dose, $3 \mathrm{mg} / \mathrm{kg})$.

\section{Discussion}

Inflammation is a complex pathophysiological phenomenon associated with numerous human diseases. Antrodia cinnamomea, a unique traditional Chinese medicine deriving from Taiwan, has several reported evidences of its biological activities, especially anti-inflammatory and anti-cancer activities. This study was elucidated the molecular mechanism of $4 \mathrm{AAQB}$, the component in mycelium extract of A. cinnamomea, on inflammation in LPS-stimulated macrophages model and LPS/CLP-induced septic models.

LPS is a well-known endotoxin to induce the activation of monocytes/macrophages, which then release inflammatory cytokines and causes septic shock [21]. Most chronic inflammatory diseases are associated with inflammatory cytokines overproduction. A previous study demonstrated that the anti-inflammatory activity of methanol extract from A. cinnamomea mycelia (MEMAC) via inhibiting iNOS and COX-2 expression and decreasing TNF- $\alpha$ and IL- 6 production. Camphorataanhydride $\mathrm{A}$ and camphorataimide $\mathrm{B}$ were isolated from MEMAC and belonging to the succinic acid derivative [11]. Another study has reported that the water extract of A. cinnamomea mycelium inhibited the production of TNF- $\alpha$, IL-1 $\beta, N O$ and PGE2, and iNOS and COX-2 expression in macrophages [22]. However, the active component is not clarified. In the present study, we demonstrated that $4 \mathrm{AAQB}$, a component from A. cinnamomea mycelium, inhibits LPS-induced TNF- $\alpha$ and IL-6 production (Fig. 2). Furthermore, 4AAQB decreased NO production via suppressing iNOS expression (Fig. 4a). This result is consistent with the previous study [15], which has shown that antroquinonol and 4acetylantroquinonol B (same as $4 \mathrm{AAQB}$ in our study) inhibited NO production and iNOS expression induced by LPS. $4 \mathrm{AAQB}$ is the third abundant compound in the ethanolic extract of mycelium, and possess better antiinflammatory activity than antroquinonol, indicating that $4 \mathrm{AAQB}$ has the potential for use as an antiinflammatory agent. We further clarify the molecular mechanism of 4AAQB and its anti-inflammatory effect in in vivo models.

Cell motility is one of the characteristics of activated monocytes/macrophages to infiltrate from blood vessels and migrate to the sites of inflammation to clear pathogens and defend inflammation process. Therefore, the ability of leukocytes migration is a good inflammation index. 4AAQB was shown its inhibitory effect in LPSinduced peritoneal macrophages migration (Fig. 3).

Upon LPS ligated to toll-like receptor 4 (TLR4) triggers the association with myeloid differentiation primary-response protein 88 (MyD88) and activates several intracellular signaling pathways, including MAPK

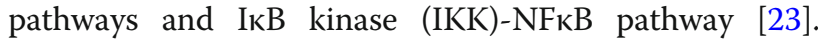
Treatment of 4AAQB significantly inhibited LPSinduced MAPK phosphorylation, including ERK1/2, p38 and JNK (Fig. 5a), which are the key elements for cell migration, proinflammatory cytokines production and inducible enzyme expression (e.g. iNOS). NFKB is another major pathway and activated during the inflammatory response to LPS. In resting cells, NFKB proteins are predominantly in cytoplasmic and associated with members of the inhibitory IкB to inhibit its DNAbinding activity. When cells activate, IкB undergoes phosphorylation and further ubiquitination and degradation, leading to $\mathrm{NFKB}$ dissociate from complex and induces an inflammatory response [20]. We found that 4AAQB inhibits LPS-induced phosphorylation of IKB and NFkB subunit p65 in RAW264.7 macrophages (Fig. 5b). STAT1 is another transcription factor involved in LPS induced inflammatory process [24]. Upon LPS stimulation, STAT1 activates in macrophages and plays a role in inflammatory process [25] and the previous study has demonstrated that STAT1 signaling is essential for iNOS overexpression in LPS-stimulated macrophages [26]. 4AAQB suppresses the phosphorylation of STAT1 stimulated by LPS (Fig. 5c) as well as iNOS expression (Fig. 4b). Taken together, our data indicated that 4AAQB exerts anti-inflammatory effects by suppressing macrophage activation via MAPK, NFkB, and STAT1 pathway.

The LPS and CLP septic model were used to investigate the effects of $4 \mathrm{AAQB}$ on acute inflammation in vivo. In LPS-induced endotoxemic model, we found that serum proinflammatory cytokine, including TNF- $\alpha$ and IL-6 were reduced in $4 \mathrm{AAQB}$-treated septic mice (Fig. 6). CLP is a more clinically relevant sepsis model than injection of endotoxin (LPS). Cecum puncture causes its bacteria inside releasing and result in polymicrobial peritonitis. Bacteria translocates into the blood and lead to septic shock, multi-organ dysfunction and ultimately death [27]. Thus, CLP is considered a good method for the investigation of the pathogenesis of sepsis. We further examined the effect of $4 \mathrm{AAQB}$ on CLP-induced septic mice. In CLP septic model, we observed that TNF- $\alpha$ and IL- 6 are markedly reduced in $4 \mathrm{AAQB}$-treated mice, and the survival rate is also improved by $4 \mathrm{AAQB}$ treatment. Furthermore, 4AAQB has shown protective effect from organ leukocyte infiltration (lung, liver and kidney) due to sepsis (Fig. 7). To our best knowledge, this study is firstly demonstrated that $4 \mathrm{AAQB}$ exhibits anti-inflammatory efficacy in in vivo models. 


\section{Conclusion}

In conclusion, $4 \mathrm{AAQB}$, an antroquinonol derivative, possesses anti-inflammatory effects in both pro-inflammatory cytokine and NO release reduction in LPS-stimulated RAW 264.7 cells via the mechanisms of inhibiting NOS2 protein expression and modulating MAPK, STAT-1 and NFkB pathways. 4AAQB also exhibit anti-inflammatory effect in LPS and CLP-induced sepsis mice model, suggesting that $4 \mathrm{AAQB}$ has effective anti-inflammatory properties and may be a therapeutic candidate which used in inflammatory disorders treatment.

\section{Additional file}

Additional file 1: Structure elucidation by NMR - The assignment of the ${ }^{1} \mathrm{H}$ NMR and ${ }^{13} \mathrm{C}$ NMR spectrum supports the proposed structure for 4AAQB. The ${ }^{1} \mathrm{H}$ NMR, ${ }^{13} \mathrm{C}$ NMR spectrum were shown in Figure S1 and Figure S2. (DOCX 1109 kb)

\section{Abbreviations}

4AAQB: 4-acetylantroquinonol B; A. cinnamomea: Antrodia cinnamomea; CLP: Cecal Ligation Puncture; LPS: Lipopolysaccharide

\section{Acknowledgments}

This work was supported by the Ministry of Science and Technology of Taiwan [grant numbers 102-2320-B-715-002-MY2]; Mackay Medical College [grant number MMC-1031A02, 1042E01, 1051C01, 1051E01, 1051B08, 1061 E02 and 1061B22].

\section{Availability of data and materials}

All data generated or analysed during this study are included in this published article and its supplementary information files.

\section{Authors' contributions}

Conceived and designed the experiments: C Chung; Performed the experiments: C Chang, $\mathrm{CH}, \mathrm{SW}, \mathrm{KL}$ and WH; Analyzed the data: C Chang, HP, C Chung; Contributed materials purified/analysis tools: WC; Wrote the manuscript: C Chang and $C$ Chung. All authors have read and approved this manuscript for publication.

\section{Ethics approval}

All the experimental protocols regarding animal studying have been approved by the Laboratory Animal Use Committee of MacKay Medicine College.

\section{Consent for publication}

Not applicable.

\section{Competing interests}

The authors declare that they have no competing interests.

\section{Publisher's Note}

Springer Nature remains neutral with regard to jurisdictional claims in published maps and institutional affiliations.

\section{Author details}

${ }^{1}$ Institute of Pharmacology, College of Medicine, National Taiwan University, Taipei, Taiwan. ${ }^{2}$ Medical and Pharmaceutical Industry Technology and Development Center, New Taipei City, Taiwan. ${ }^{3}$ Department of Medicine, Mackay Medical College, No. 46, Sec. 3, Jhong-Jheng Rd., Sanzhi Dist, New Taipei City, Taiwan. ${ }^{4}$ Department of Pharmacology and Toxicology, Tzu Chi University, Hualien, Taiwan.
Received: 23 December 2016 Accepted: 15 March 2018

Published online: 23 March 2018

\section{References}

1. Medzhitov R. Origin and physiological roles of inflammation. Nature. 2008; 454(7203):428-35.

2. Gaestel M, Kotlyarov A, Kracht M. Targeting innate immunity protein kinase signalling in inflammation. Nat Rev Drug Discov. 2009;8(6):480-99.

3. Lawrence T, Willoughby DA, Gilroy DW. Anti-inflammatory lipid mediators and insights into the resolution of inflammation. Nat Rev Immunol. 2002; 2(10):787-95.

4. Angus DC, van der Poll T. Severe sepsis and septic shock. N Engl J Med. 2013:369(21):2063.

5. Ding JL, Li P, Ho B. The sushi peptides: structural characterization and mode of action against gram-negative bacteria. Cell Mol Life Sci. 2008;65(7-8): 1202-19.

6. Van Amersfoort ES, Van Berkel TJ, Kuiper J. Receptors, mediators, and mechanisms involved in bacterial sepsis and septic shock. Clin Microbiol Rev. 2003;16(3):379-414.

7. Ao ZH, Xu ZH, Lu ZM, Xu HY, Zhang XM, Dou WF. Niuchangchih (Antrodia camphorata) and its potential in treating liver diseases. J Ethnopharmacol. 2009;121(2):194-212

8. Lu MC, El-Shazly M, Wu TY, Du YC, Chang TT, Chen CF, Hsu YM, Lai KH, Chiu CP, Chang FR, et al. Recent research and development of Antrodia cinnamomea. Pharmacol Ther. 2013;139(2):124-56.

9. Geethangili M, Tzeng YM. Review of pharmacological effects of Antrodia camphorata and its bioactive compounds. Evid Based Complement Alternat Med. 2011;2011:212641.

10. Hsiao G, Shen MY, Lin KH, Lan MH, Wu LY, Chou DS, Lin CH, Su CH, Sheu JR. Antioxidative and hepatoprotective effects of Antrodia camphorata extract. J Agric Food Chem. 2003;51(11):3302-8.

11. Wen CL, Chang CC, Huang SS, Kuo CL, Hsu SL, Deng JS, Huang GJ. Antiinflammatory effects of methanol extract of Antrodia cinnamomea mycelia both in vitro and in vivo. J Ethnopharmacol. 2011;137(1):575-84.

12. Lin YW, Pan JH, Liu RH, Kuo YH, Sheen LY, Chiang BH. The 4acetylantroquinonol $\mathrm{B}$ isolated from mycelium of Antrodia cinnamomea inhibits proliferation of hepatoma cells. J Sci Food Agric. 2010;90(10):1739-44.

13. Chang C, Huang T, Lin K, Hsu C, Chang W, Wang S, Ko F, Peng H, Chung C. 4-Acetylantroquinonol B suppresses tumor growth and metastasis of hepatoma cells via blockade of translation-dependent signaling pathway and VEGF production. J Agric Food Chem. 2015:63(1):208-15.

14. Lin YW, Chiang BH. 4-acetylantroquinonol B isolated from Antrodia cinnamomea arrests proliferation of human hepatocellular carcinoma HepG2 cell by affecting p53, p21 and p27 levels. J Agric Food Chem. 2011; 59(16):8625-31.

15. Wang HC, Chu FH, Chien SC, Liao JW, Hsieh HW, Li WH, Lin CC, Shaw JF, Kuo YH, Wang SY. Establishment of the metabolite profile for an Antrodia cinnamomea health food product and investigation of its chemoprevention activity. J Agric Food Chem. 2013;61(36):8556-64.

16. Dileepan KN, Page JC, Li Y, Stechschulte DJ. Direct activation of murine peritoneal macrophages for nitric oxide production and tumor cell killing by interferon-gamma. J Interf Cytokine Res. 1995;15(5):387-94.

17. Kim JB, Han AR, Park EY, Kim JY, Cho W, Lee J, Seo EK, Lee KT. Inhibition of LPS-induced iNOS, COX-2 and cytokines expression by poncirin through the NF-kappaB inactivation in RAW 264.7 macrophage cells. Biol Pharm Bull. 2007;30(12):2345-51.

18. Heo SK, Yun HJ, Noh EK, Park WH, Park SD. LPS induces inflammatory responses in human aortic vascular smooth muscle cells via toll-like receptor 4 expression and nitric oxide production. Immunol Lett. 2008; 120(1-2):57-64.

19. Cargnello M, Roux PP. Activation and function of the MAPKs and their substrates, the MAPK-activated protein kinases. Microbiol Mol Biol Rev. 2011; 75(1):50-83.

20. Moynagh PN. The NF-kappaB pathway. J Cell Sci. 2005;118(Pt 20):4589-92.

21. Beutler B, Rietschel ET. Innate immune sensing and its roots: the story of endotoxin. Nat Rev Immunol. 2003;3(2):169-76.

22. Hseu YC, Wu FY, Wu JJ, Chen JY, Chang WH, Lu FJ, Lai YC, Yang HL. Antiinflammatory potential of Antrodia Camphorata through inhibition of iNOS, COX-2 and cytokines via the NF-kappaB pathway. Int Immunopharmacol. 2005;5(13-14):1914-25. 
23. Akira S, Takeda K. Toll-like receptor signalling. Nat Rev Immunol. 2004;4(7): 499-511.

24. Rhee SH, Jones BW, Toshchakov V, Vogel SN, Fenton MJ. Toll-like receptors 2 and 4 activate STAT1 serine phosphorylation by distinct mechanisms in macrophages. J Biol Chem. 2003;278(25):22506-12.

25. Levy DE, Darnell JE Jr. Stats: transcriptional control and biological impact. Nat Rev Mol Cell Biol. 2002;3(9):651-62.

26. Tsoyi K, Kim HJ, Shin JS, Kim DH, Cho HJ, Lee SS, Ahn SK, Yun-Choi HS, Lee $J \mathrm{H}$, Seo HG, et al. HO-1 and JAK-2/STAT-1 signals are involved in preferential inhibition of iNOS over COX-2 gene expression by newly synthesized tetrahydroisoquinoline alkaloid, CKD712, in cells activated with lipopolysacchride. Cell Signal. 2008;20(10):1839-47.

27. Siempos II, Lam HC, Ding Y, Choi ME, Choi AM, Ryter SW. Cecal ligation and puncture-induced sepsis as a model to study autophagy in mice. J Vis Exp. 2014;84:e51066.

Submit your next manuscript to BioMed Central and we will help you at every step:

- We accept pre-submission inquiries

- Our selector tool helps you to find the most relevant journal

- We provide round the clock customer support

- Convenient online submission

- Thorough peer review

- Inclusion in PubMed and all major indexing services

- Maximum visibility for your research

Submit your manuscript at www.biomedcentral.com/submit
Biomed Central 